Research Article

\title{
Thermal Insulation Performance of Radiant Barrier Roofs for Rural Buildings in the Qinba Mountains
}

\author{
Yiyun Zhu (iD) and Xianling Wang (D) \\ School of Civil and Architectural Engineering, Xi'an University of Technology, Xi'an 710048, China \\ Correspondence should be addressed to Yiyun Zhu; zhuyiyun006@126.com
}

Received 24 March 2020; Accepted 7 April 2020; Published 29 April 2020

Academic Editor: Yumin Cheng

Copyright (C) 2020 Yiyun Zhu and Xianling Wang. This is an open access article distributed under the Creative Commons Attribution License, which permits unrestricted use, distribution, and reproduction in any medium, provided the original work is properly cited.

\begin{abstract}
Strengthening the roof insulation is the main method for improving the indoor thermal environment of rural buildings during summer. This study proposed a radiant barrier roof with a roof insulation structure based on climatic conditions in the Qinba Mountains and the characteristics of rural buildings, in which radiant barriers were installed on the underside of the roof in the attic space to enhance roof insulation. To study the thermal insulation performance of radiant barrier roofs, aluminum foil bubble composites were installed on the underside of the roof in the attic space in the Qinba Mountains, and comparative experiments were carried out. Based on the results, the average temperature of the second-floor bedrooms dropped by $1.1^{\circ} \mathrm{C}$, thus proving the effectiveness of thermal insulation with radiant barrier roofs. The thermal insulation performance of radiant barrier roofs made of aluminum foil bubble composite was studied through numerical simulation analysis. Based on the findings of this study, radiant heat transfer contributed $65 \%$ to the thermal insulation effect when aluminum foil bubble composites were applied. Based on the analysis of thermal performance and cost, it is recommended to use radiant barrier materials with an emissivity of less than 0.3 and a thermal resistance of no more than $2 \mathrm{~m}^{2} \mathrm{~K} / \mathrm{W}$. Furthermore, the application of radiant barrier roofs made of aluminum foil bubble composites can have a positive effect on thermal insulation during winter. This facilitates the widespread use of radiant barrier roofs for rural buildings throughout hot-summer/cold-winter zones.
\end{abstract}

\section{Introduction}

At present, energy consumption in buildings accounts for $36 \%$ of total energy consumption in China, while the area of rural buildings and residences is approximately three times that of urban residences $[1,2]$. Rural buildings have indoor thermal environments of poor quality. When the per capita income of villagers increases to a certain level as the economy grows, energy consumption in rural buildings will rise in a nonlinear manner, and the total energy consumption of rural buildings will exceed that of urban areas. Therefore, faced with the rapid development of urbanization-driven construction, improving indoor thermal environments in rural buildings based on local conditions is the main way to realize green and livable rural areas and has important strategic significance for building a sustainable and harmonious society.
Enclosure structures are an important factor affecting indoor thermal environments during summer. The roof is the main source of heat loss in the enclosure structure of buildings, constituting $70 \%$ of total heat loss, because roofs are exposed to solar radiation all day long [3-5]. Therefore, it is especially important to strengthen roof insulation structures. At present, studies on roof insulation design primarily focus on superinsulating materials $[6,7]$, green roofs $[8,9]$, natural ventilation techniques $[10,11]$, reflection techniques $[12,13]$, and other techniques [14-16]. A type of smooth and thin aluminum foil layer with low emissivity and high reflectivity is used in reflection techniques to reduce radiant heat transfer in air [17-19]. Reflection techniques include cold roofs and radiant barriers, both of which reduce radiant heat transfer in air to lower the quantity of heat flowing into the living space through the roof $[20,21]$. 
The energy-saving design of buildings in hot-summer/ cold-winter zones in China is mainly based on heat protection during summer and also takes into account thermal insulation during winter. The Qinba Mountains are located in a northern high-latitude region within a hot-summer/ cold-winter zone in China. In such zones, the temperature difference between day and night during summer is small, and solar radiation is stronger in the same season, whereas winter temperature is low, and solar radiation is still acceptable in the same season; therefore, these zones have a certain potential to utilize such a design. Moreover, the air in these zones contains large amounts of moisture, resulting in typical regional climatic conditions, including hot and humid summer, as well as wet and cold winter. According to surveys, most local houses use rafter tile-type roofs in the attic space for roof insulation. Heat transfer takes place mainly in the air layer within the attic space via convection and radiation. The roof tiles conduct heat to the inner surface of the roof tiles owing to exposure to sunlight during the day. Then, heat in the roof tiles is transferred to the cooler roof panels via radiation and convection. Due to the large temperature difference between the roof tiles and the roof panels during summer, radiant heat transfer constitutes a higher proportion than convective heat transfer [22].

Regulating radiant heat transfer in the attic space reduces the quantity of heat entering indoors through the roof. Despite being significantly effective, cold roofs will be covered with dust and moss after being used for a few years, which, in turn, reduces the reflectivity of the roof tiles and enhances living space heating (Figure 1); therefore, this technique is not suitable for these zones. Installing radiant barriers on the bottom surface of the roof tiles in the attic space can effectively prevent dust accumulation and reduce radiant heat transfer in the air layer within the attic space [23-26].

Applying radiant barriers to the roof in the attic space is a feasible thermal insulation measure. To assess the actual effects of radiant barriers in the attic space, Ferreira and Corvacho [27] conducted field tests on two buildings in northern Portugal, and the results showed that radiant barriers can effectively reduce maximum indoor temperature. Medina [28] found that a small change in the emissivity of radiant barriers will result in a significant change in heat flux during summer, while reducing heat flowing into indoor space during winter. In recent years, to improve indoor thermal comfort, certain new aluminum foil composites have appeared in radiation barriers, and a layer of insulating materials has been added in the middle of radiant barriers. This kind of insulating material further reduces the quantity of heat flowing into the attic space through the roof tiles. Kosny et al. [29] tested the thermal insulation effect of the new aerogel-based radiant barriers installed in the attic space and found that the thermal load in the attic space installed with radiant barriers decreased significantly. Reduced thermal load is the result of the combined effect of low emissivity and thermal resistance; however, their study failed to point out the contribution of aerogel-based radiant barriers to radiant heat transfer.
Based on the abovementioned research background, this study proposes a type of roof insulation structure, namely, a radiant barrier roof, which consists of a pitched roof, radiant barriers, and an attic space. Figure 2 shows the structure of the radiant barrier roof. This roof insulation structure is expected to be extended to rural buildings in hot-summer/ cold-winter zones. This is because residents will also install a ceiling in their homes, which can also form an attic-like space, for decoration purposes, even though most rural buildings currently do not have an attic space. To promote the use of radiant barrier roofs in the Qinba Mountains and assist in designing them, it is necessary to study the thermal insulation performance of radiant barrier roofs and conduct a parametric analysis of the emissivity and thermal resistance of radiant barriers.

To study the thermal insulation performance of a radiant barrier roof, the research team conducted a field experiment in the indoor thermal environment of rural buildings in the Qinba Mountains in the summer of 2019 as well as studied the thermal insulation performance of radiant barrier roofs made of aluminum foil bubble composite through numerical simulation analysis and drew corresponding conclusions. This study provides new ideas and methods of thermal insulation for rural buildings situated in the Qinba Mountains during summer and is of guiding value to rural constructions in the context of rural revitalization.

\section{Materials and Methods}

2.1. Field Experiment. A comparative experiment was conducted on the thermal performance of radiant barriers under the climatic conditions of Jinxing Village, Hanzhong City, from July 27 to 28, 2019. The experiment was performed on two parallel buildings with similar characteristics (Figure 3). Both buildings were very similar in terms of structure and could be used in the comparative experiment. Nevertheless, they were not identical: Residence 1 had a smaller attic area than Residence 2 (the plan dimensions of Residence 2 were $12.6 \mathrm{~m} \times 8.9 \mathrm{~m}$, while the plan dimensions of Residence 1 were $14.4 \mathrm{~m} \times 9.5 \mathrm{~m}$ ). To seek conditions that were as similar as possible, the second floors of both buildings were uninhabited, and the windows were closed. The type of roof involved was a pitched roof with a slope of $30^{\circ}$, erected by directly installing roof tiles on the rafters without an insulation layer. Meanwhile, the outer wall was a $240 \mathrm{~mm}$ thick solid clay brick wall, with plaster applied to the inner and outer walls but without a thermal insulation layer. Considering that aluminum foil bubble composites are easy to install, low cost, and high efficiency, radiant barriers were made of aluminum foil bubble composites. In Residence 1, aluminum foil bubble composites were applied to the inner surface of the roof tiles in the attic space and directly covered the rafters. By contrast, the structure of the attic space in Residence 2 remained unchanged (Figure 4).

The content of the experiment comprised indoor and outdoor air temperatures, wall temperature, and solar radiation intensity. The test equipment was placed at similar positions in both residences. Air temperature was measured using the TR-72U hygrothermograph, with a test accuracy of 


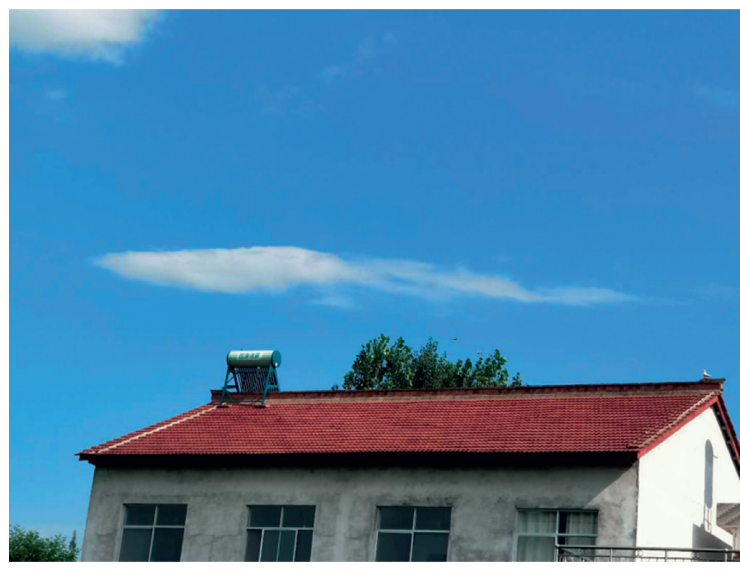

(a)

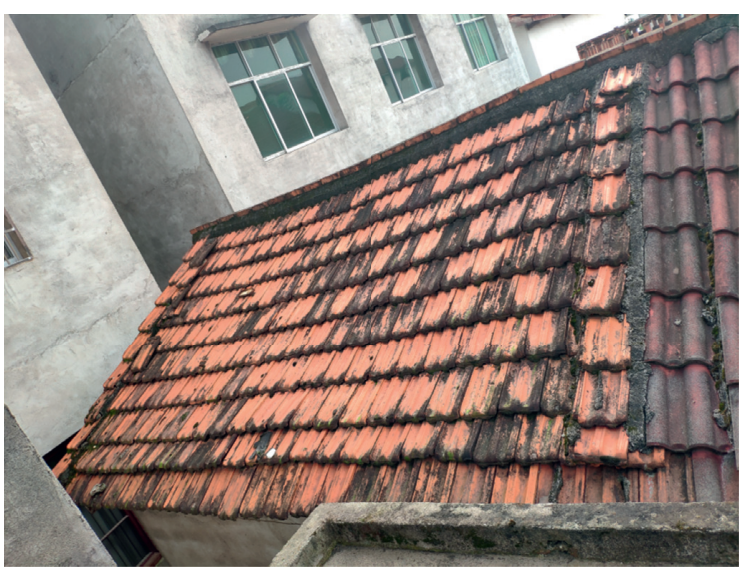

(b)

Figure 1: (a) Roof of a new building. (b) A roof covered with dust and moss.

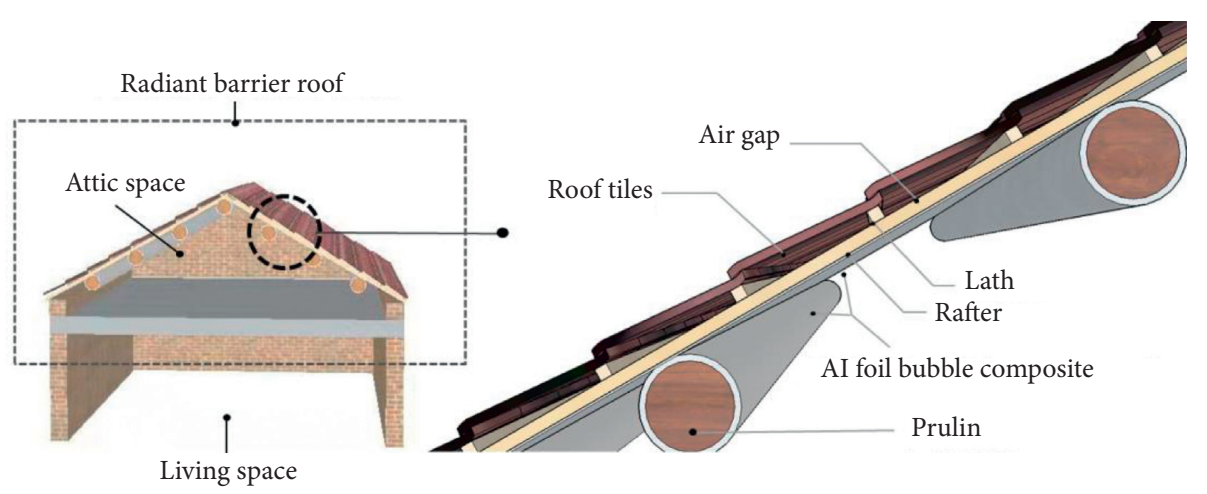

FIgURE 2: Radiant barrier roof structure.

$\pm 0.2^{\circ} \mathrm{C}$. Three hygrothermographs were used in Residence 1 , placed in the attic space, second-floor bedroom, and outdoors, where the outdoor hygrothermograph was placed in a location away from direct sunlight. Two hygrothermographs were used in Residence 2, placed in the attic space and second-floor bedroom. Wall temperature was measured using the LR5021 thermocouple, with a test accuracy of $\pm 0.5^{\circ} \mathrm{C}$. The experiment was performed continuously for 24 hours, and data were collected at one-hour intervals. In Residence 1, thermocouples were used to test temperatures at the top of the south-facing roof tiles, the bottom of the roof tiles, the top of the radiant barriers, the bottom of the radiant barriers, the attic floor, the bedroom ceiling, and the outer walls of the attic (in all four directions). Since both Residence 1 and Residence 2 have very similar structures, only the outer surface of the enclosure structure in Residence 1 was measured. In Residence 2, thermocouples were used to measure the wall temperatures of the bottom surface of the south-facing roof tiles, the attic floor, and the bedroom ceiling. Figure 5 shows the layout of the measuring points, while Figure 6 displays the location of some thermocouples. Meanwhile, solar radiation intensity was measured using the TBD-1 radiometer and TBQ-2 pyranometer, where the measurement range of the pyranometer is 0 to $2000 \mathrm{~W} / \mathrm{m} 2$, and the sensitivity coefficient of the pyranometer is
$8.789 \mu \mathrm{V} /\left(\mathrm{W} \cdot \mathrm{m}^{-2}\right)$. Data were collected at one-hour intervals, while the measuring points were located in an outdoor open space with an unobstructed surrounding area.

2.2. Numerical Analysis. ANSYS CFX (SIMULIA Inc., USA) is currently one of the most comprehensive, versatile, and widely used types of CFD software in China. ANSYS CFX is the world's only large-scale commercial software that uses a fully implicit coupling algorithm. Pressure-velocity coupling is achieved using the semi-implicit method for pressurelinked equations (SIMPLE) algorithm. The software adopts the element-based finite volume method and absorbs the numerical accuracy of the finite element method by ensuring the conservative features of the finite volume method. ANSYS CFX has a common physical model that includes flow, heat transfer, and radiation. Advanced algorithms, a wide range of physical models, and powerful pre- and postprocessing capabilities enable ANSYS CFX to demonstrate excellent performance in terms of result accuracy, computational stability, and flexibility. Therefore, ANSYS CFX was employed in this study. Experimental data were used for validating the CFX model, while the validated model was used for quantifying the contribution of radiant heat transfer and heat conduction to the reduction of peak 


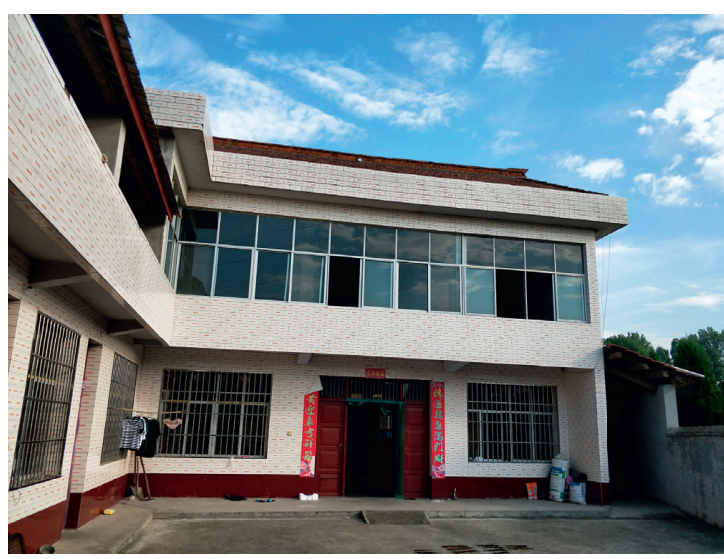

(a)

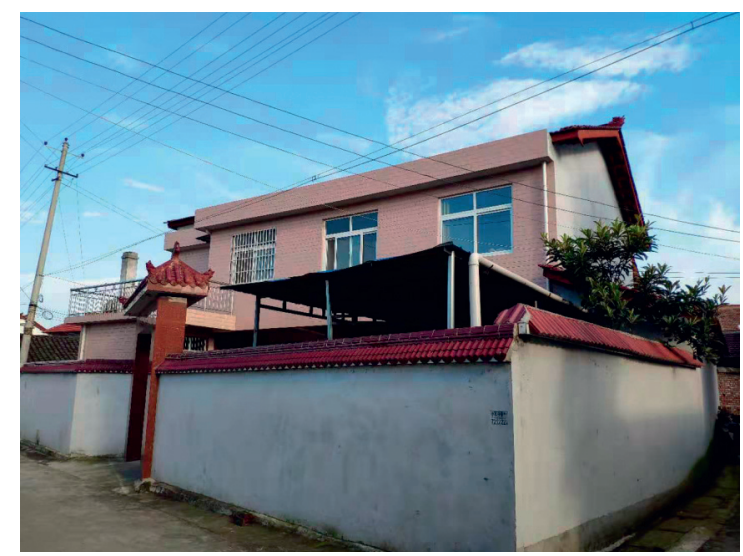

(b)

Figure 3: Buildings in the experiment: (a) Residence 1 and (b) Residence 2.

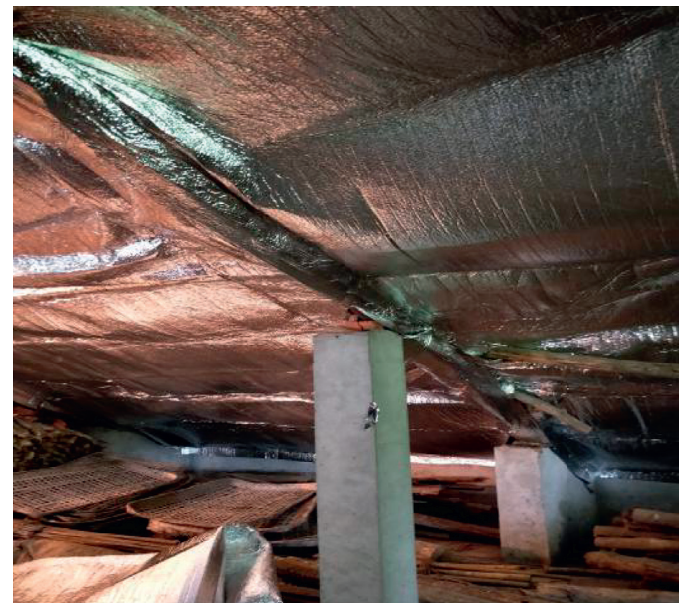

(a)

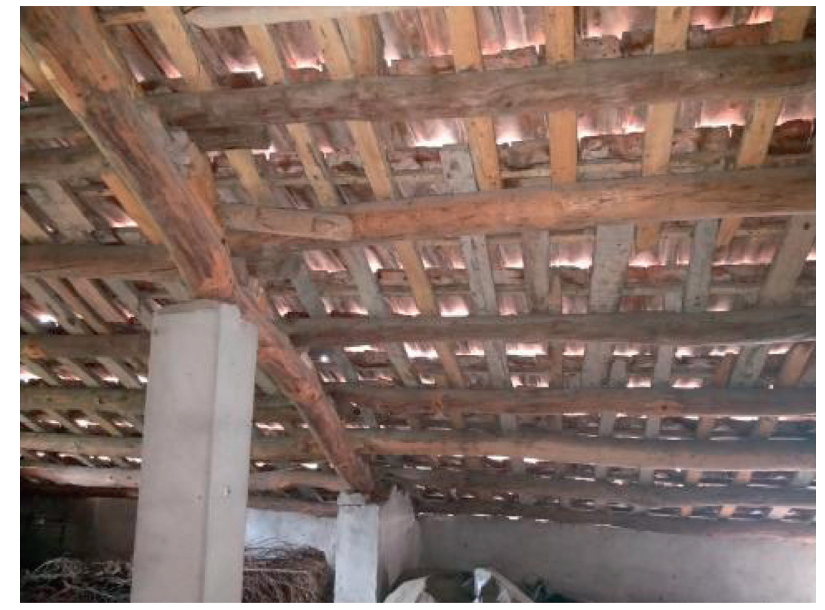

(b)

Figure 4: Position of radiant barriers in (a) Residence 1 and (b) Residence 2.

ceiling temperature when aluminum foil bubble composites were applied. In addition, this study also simulated the effect of emissivity and thermal resistance on the peak temperature of the bedroom ceiling. Last, this study investigated the effects of the application of aluminum foil bubble composites to radiant barrier roofs during winter.

\subsubsection{Physical Model and Material Composition.} Considering that the subject of this study is the attic space, the model was properly simplified to reduce the number of model calculations, while a three-dimensional model was constructed to test the attic space and the second floor (onemeter tall) of the buildings. Since both test residences had very similar structures, only the three-dimensional model for Residence 1 was constructed to represent two similar residential buildings. The model performed grid generation using hexahedral and tetrahedral grids, where the number of grid points was 685,200 . Figure 7 shows the grid of the model. Fluid density is related to pressure and temperature.
When a fluid is in a natural convection state, the density of the fluid mainly depends on temperature, but the effect of pressure is negligible. To enable the governing equations to converge more easily, the Boussinesq model was employed to consider the effect of air lift on the calculation results, namely, $\rho=\rho_{0}(1-\beta \Delta T) g$ [30]. The Monte Carlo model was adopted in the radiation model, while the most commonly used $k-\varepsilon$ standard model was employed in the turbulence model $[31,32]$. The material dimensions and thermal parameters for the building structures were set according to Tables 1 and 2, where $d$ is the thickness, $\rho$ is the density, $\lambda$ is the thermal conductivity, $c$ is the specific heat capacity, $r$ is the thermal resistance, and $\varepsilon$ is the surface emissivity.

2.2.2. Control Equations. Indoor heat transfer follows three basic conservation laws, namely, the laws of conservation of energy, conservation of mass, and conservation of momentum. These are described numerically through the general control equation as follows: 

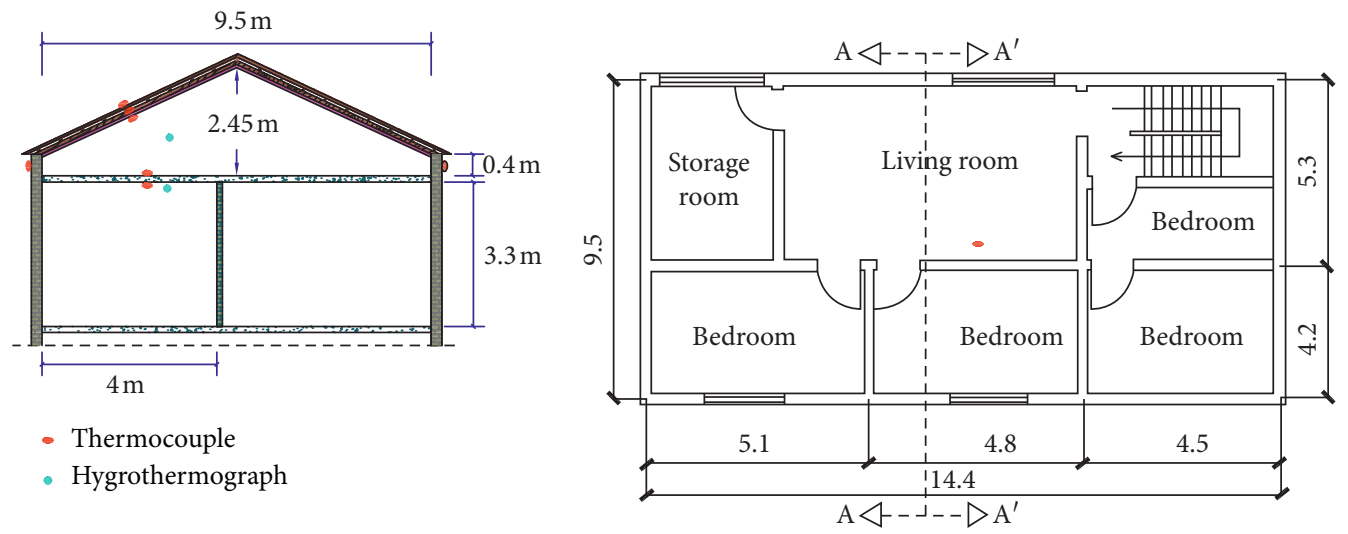

(a)
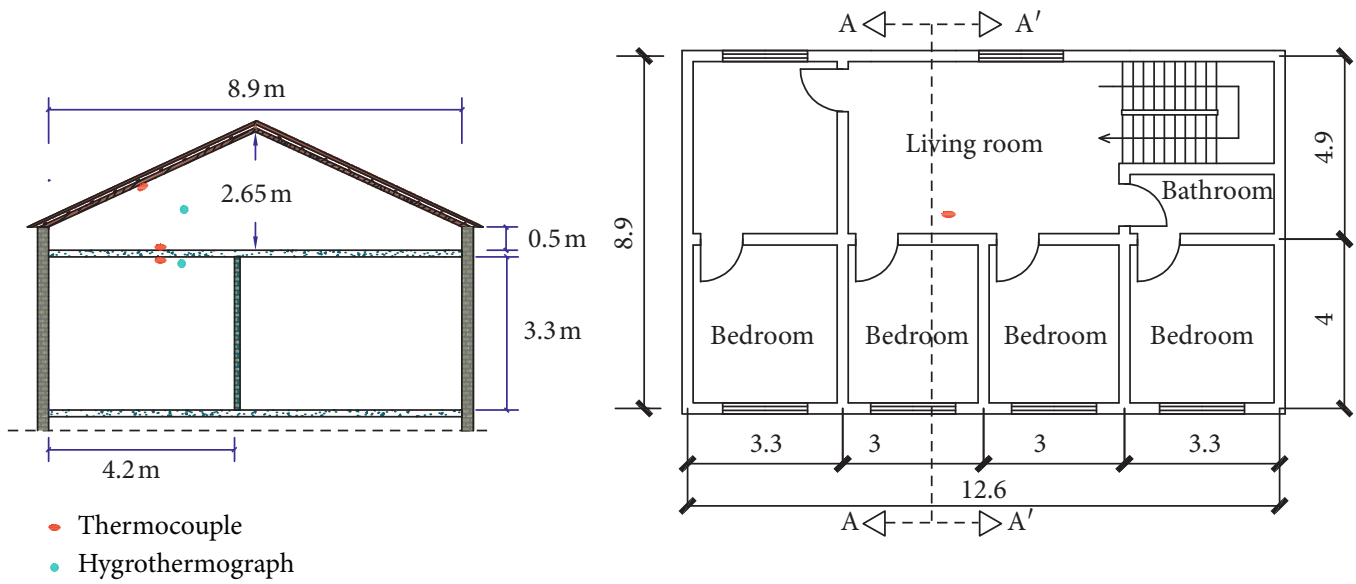

(b)

Figure 5: Measuring points in (a) Residence 1 and (b) Residence 2.

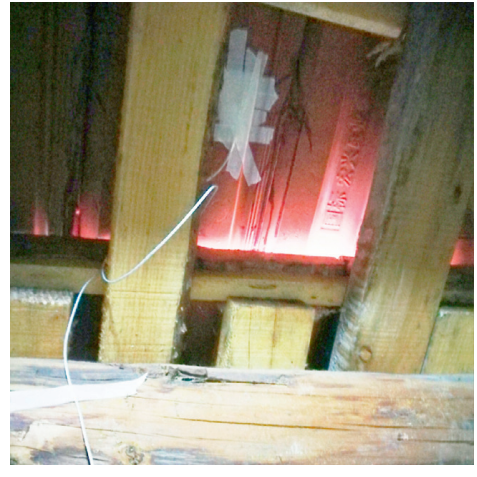

(a)

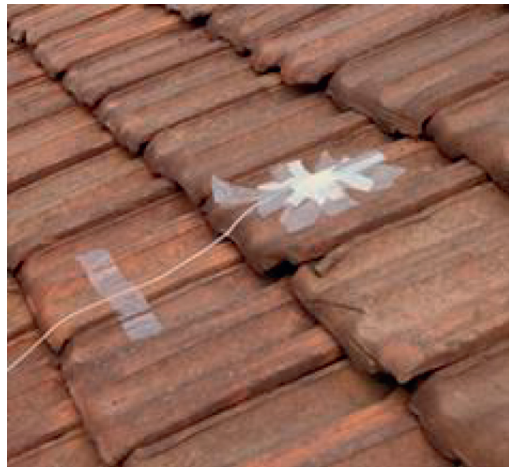

(b)

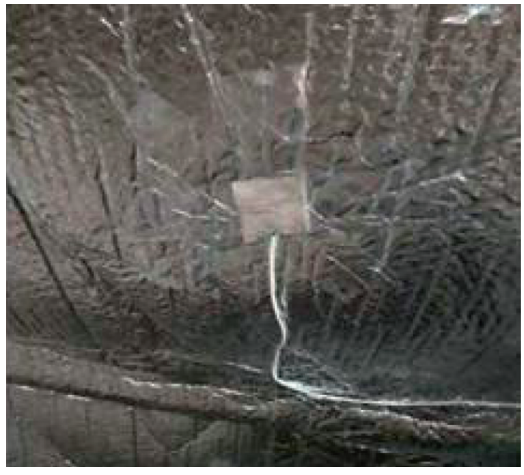

(c)

FIgURE 6: Type $T$ thermocouples applied to the surface.

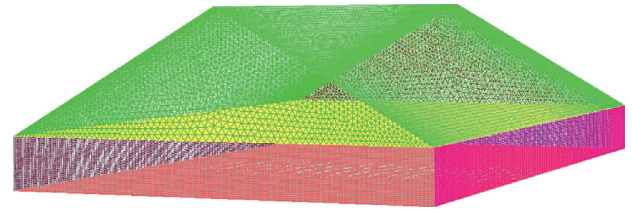

Figure 7: Grid of the model.

$$
\frac{\partial \rho \varphi}{\partial t}+\operatorname{div}(\rho v \varphi)=\operatorname{div}(\Gamma \cdot \operatorname{grad} \varphi)+S_{\varphi}
$$

where $(\partial \rho \varphi / \partial t)$ is the unsteady term; $\operatorname{div}(p v \varphi)$ is the convection term; $\operatorname{div}(\Gamma \cdot \operatorname{grad} \varphi)$ is the diffusion term; $\Gamma$ is the generalized diffusion coefficient; and $S_{\varphi}$ is the source term. 
TABLE 1: Parameters of building materials.

\begin{tabular}{lcccccc}
\hline Project & Material & $\begin{array}{c}d \\
(\mathrm{~mm})\end{array}$ & $\begin{array}{c}\rho \\
\left(\mathrm{kg} / \mathrm{m}^{3}\right)\end{array}$ & $\begin{array}{c}\lambda \\
(\mathrm{W} / \mathrm{m} \mathrm{K})\end{array}$ & $\begin{array}{c}\mathrm{c} \\
(\mathrm{J} / \mathrm{kg} \mathrm{K})\end{array}$ & $\begin{array}{c}r \\
\left(\mathrm{~m}^{2} \mathrm{~K} / \mathrm{W}\right)\end{array}$ \\
\hline Roof & Clay tile & 20 & 2000 & 1 & 800 & 0.02 \\
\hline \multirow{3}{*}{ Floor } & Cement mortar & 20 & 1800 & 0.93 & 1050 & 0.91 \\
& Concrete & 100 & 2500 & 1.74 & 920 & 0.96 \\
& Cement mortar & 20 & 1800 & 0.93 & 1050 & 0.1 \\
\multirow{3}{*}{ Wall } & Cement mortar & 20 & 1800 & 0.93 & 1050 & 0.96 \\
& Solid clay bricks & 240 & 1800 & 0.81 & 1050 & 0.34 \\
& Cement mortar & 20 & 1800 & 0.93 & 1050 & 0.96 \\
\hline
\end{tabular}

TABle 2: Parameters of aluminum foil bubble composites.

\begin{tabular}{lccccc}
\hline Material & $\begin{array}{c}d \\
(\mathrm{~mm})\end{array}$ & $\begin{array}{c}\lambda \\
(\mathrm{W} / \mathrm{m} \mathrm{K})\end{array}$ & $\begin{array}{c}\rho \\
\left(\mathrm{kg} / \mathrm{m}^{3}\right)\end{array}$ & $\begin{array}{c}\mathrm{c} \\
(\mathrm{J} / \mathrm{kg} \mathrm{K})\end{array}$ & $\begin{array}{c}r \\
\left(\mathrm{~m}^{2} \mathrm{~K} / \mathrm{W}\right)\end{array}$ \\
\hline Aluminum foil bubble composites & 3 & 0.04 & 93 & 932 & $\mathrm{E}$ \\
\hline
\end{tabular}

The turbulence kinetic energy equation ( $k$-equation) in the standard $k-\varepsilon$ two-equation model is expressed as follows:

$$
\frac{\partial(\rho k)}{\partial t}+\frac{\partial\left(\rho k u_{i}\right)}{\partial x_{i}}=\frac{\partial}{\partial x_{j}}\left[\left(\mu+\frac{\mu_{t}}{\sigma_{k}}\right) \frac{\partial k}{\partial x_{j}}\right]+G_{k}+G_{b}-\rho \varepsilon-Y_{M}
$$

The turbulence dissipation equation ( $\varepsilon$-equation) is expressed as follows:

$$
\begin{aligned}
\frac{\partial(\rho \varepsilon)}{\partial t}+\frac{\partial(\rho k \varepsilon)}{\partial x_{i}}= & \frac{\partial}{\partial x_{j}}\left[\left(\mu+\frac{\mu_{t}}{\sigma_{\varepsilon}}\right) \frac{\partial \varepsilon}{\partial x_{j}}\right] \\
& +C_{1 \varepsilon} \frac{\varepsilon}{k}\left(G_{k}+C_{3 \varepsilon} G_{b}\right)-C_{2 \varepsilon} \rho \frac{\varepsilon^{2}}{k}
\end{aligned}
$$

where $G_{k}$ and $G_{b}$ are the kinetic energy generation terms arising from average velocity gradient and buoyancy. For compressible fluids,

$$
G_{b}=\beta g_{i} \frac{\mu}{P r_{t}} \frac{\partial t}{\partial x_{i}}
$$

where $t$ is the temperature, $P r_{t}$ is the Prandtl number, and $\mathrm{Pr}_{t}=0.85$ in this study. $Y_{M}$ represents the contribution of arterial dilatation in compressible turbulence. $C_{1 \varepsilon}, C_{2 \varepsilon}$, and $C_{3 \varepsilon}$ are empirical constants, while $\sigma_{k}$ and $\sigma_{\varepsilon}$ are the Prandtl numbers corresponding to turbulence kinetic energy, $k$, and dissipation rate, $\varepsilon$, respectively. The values of these parameters are shown as follows:

$$
\begin{aligned}
C_{1 \varepsilon} & =1.44, \\
C_{2 \varepsilon} & =1.92, \\
\sigma_{k} & =1.0, \\
\sigma_{\varepsilon} & =1.3 .
\end{aligned}
$$

In radiation calculations, the effective radiant energy of a surface generally includes emitted energy and reflected energy on the surface. The quantity of emitted energy on the surface is determined by the emissivity and temperature of the surface, while the quantity of reflected energy on the surface is determined by the incident energy projected from the surrounding surface and the reflectivity of the surface itself. The effective radiant energy of the surface can be expressed by the following equation:

$$
q_{o k}=\varepsilon_{k} \sigma T_{k}^{4}+\rho_{k} q_{i k},
$$

where $q_{o k}$ is the effective radiant energy of surface $k ; \varepsilon_{k}$ is the emissivity of surface $k$; i.e., $5.67 \times 10^{-8}\left(\mathrm{~W} / \mathrm{m}^{2} \mathrm{~K}^{2}\right)$; $\sigma$ is the Boltzmann constant; $\rho_{k}$ is the reflectivity of surface $k$; and $q_{i k}$ is the radiant energy projected to surface $k$.

2.2.3. Boundary Conditions. In the study of the thermal insulation performance of radiant barriers during summer, the boundary conditions for the enclosure structure were derived from measured data. The outer surface temperatures of the four walls and roof tiles tested in Residence 1 were fitted to fourth-order Fourier series using MATLAB software (MathWorks, Inc., Natick, MA, USA) and then used as the boundary conditions for the wall temperature of the enclosure structure in the numerical model (Figure 8). Meanwhile, in the study of the thermal insulation performance of radiant barriers during winter, the boundary conditions for the enclosure structure were derived from the Hanzhong typical meteorological year database [33]. Meteorological data on the winter solstice were selected for their research significance owing to the fact that the winter solstice is the day with the shortest sunshine duration in the year. As the Qinba Mountains are relatively rich in solar resources, the constructed enclosure structure not only experiences heat exchange with outdoor air but is also affected by solar radiation. To reflect the local climatic conditions more accurately, outdoor sol-air temperatures in different orientations were used as boundary conditions for the enclosure structure. Outdoor sol-air temperatures in different orientations on the winter solstice were calculated based on meteorological data. Outdoor sol-air temperature includes not only the heating effect of direct radiation, scattered radiation, ground-reflected radiation, and outdoor air temperature on the enclosure structure but also involves the scattering effect of effective long-wave radiation. 


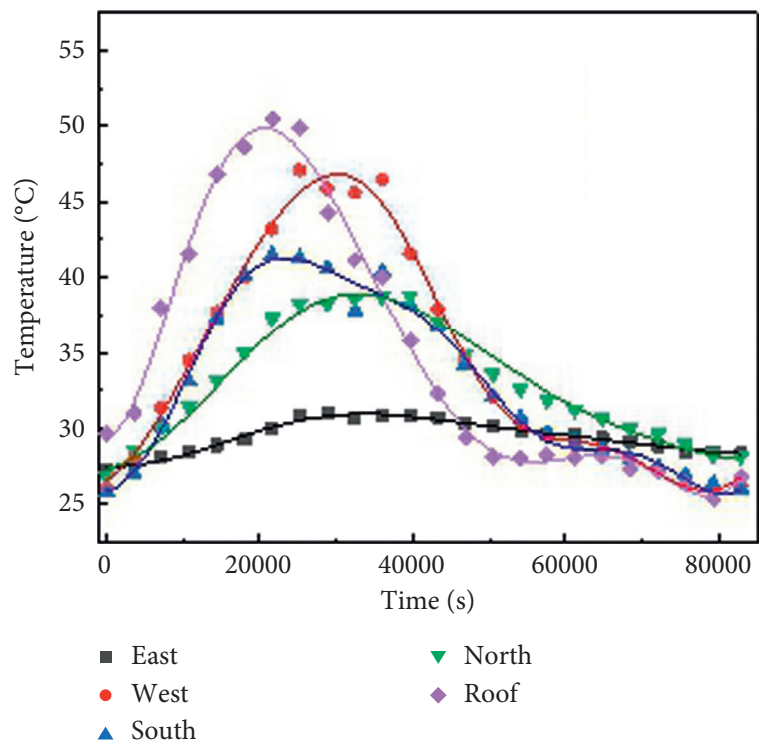

(a)

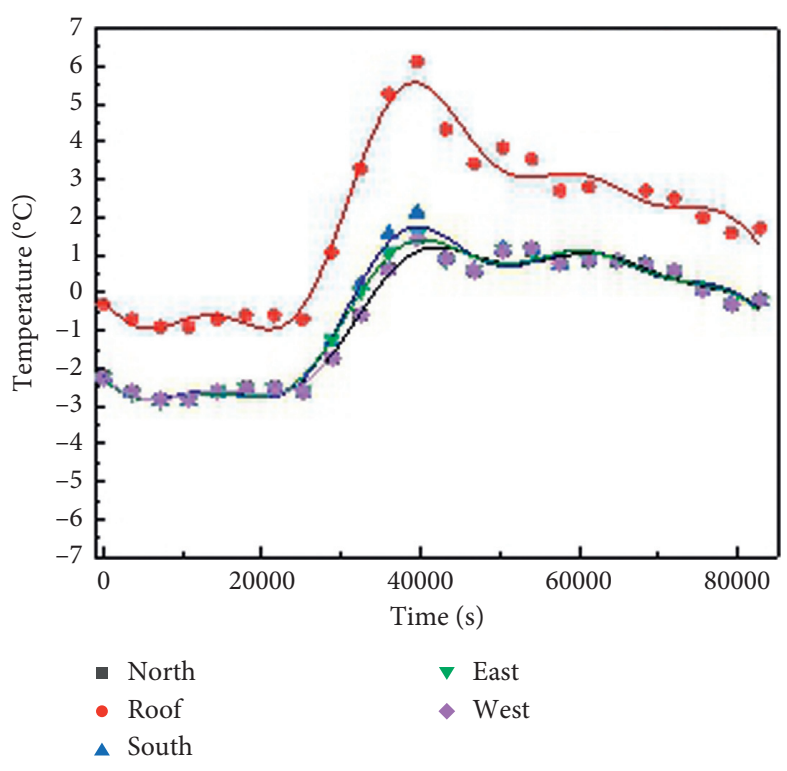

(b)

FIgURe 8: Comparison of Fourier series-based curves and discrete values of outdoor sol-air temperature during (a) summer and (b) winter.

According to [34], the outdoor sol-air temperature of the enclosure structure in different orientations during winter in Hanzhong is calculated using the following equation:

$$
t_{Z}=t_{a}+\frac{q_{S}+q_{R}}{\alpha_{a}}-\frac{q_{e}}{\alpha_{a}}
$$

where $t_{Z}$ and $t_{a}$ are outdoor sol-air temperature and outdoor air temperature $\left({ }^{\circ} \mathrm{C}\right)$, respectively, while $q_{S}$ and $q_{R}$ are the quantity of heat from ground-reflected radiation and solar radiation absorbed by the outer surface of the enclosure structure $\left(\mathrm{W} / \mathrm{m}^{2}\right)$, respectively. The absorption rate of the outer surface of the enclosure structure is $0.7 ; q_{e}$ is the effective radiation $\left(\mathrm{W} / \mathrm{m}^{2}\right)$; and $\alpha_{a}$ is the overall heat transfer coefficient of the surface.

Table 3shows the calculation results for outdoor air temperature as well as hourly outdoor sol-air temperatures in different directions on the winter solstice. Hourly sol-air temperatures were fitted to fourth-order Fourier series using MATLAB (Figure 8). Based on Figure 8, the fourthorder Fourier series-based outdoor sol-air temperature curves were basically consistent with the discrete values of hourly outdoor sol-air temperature. Therefore, the fitted external disturbance functions of the enclosure structure during winter and summer were used as the boundary conditions of the simulation. The initial indoor air temperature during summer was taken from the corresponding measured data, while the initial indoor air temperature during winter, which was derived from thermal comfort indicators, was $12^{\circ} \mathrm{C}$.

\section{Results and Discussion}

Test data were used to validate the accuracy of the ANSYS CFX model and the effectiveness of the radiant barrier roofs. Numerical model analysis was performed to quantify the contribution of radiant heat transfer and heat conduction to the reduction of peak ceiling temperature. This study also simulated and analyzed the effect of the reflectivity and thermal resistance of radiant barriers on the temperature of the bedroom ceiling. In addition, this study investigated the effect of the application of aluminum foil bubble composites during winter.

3.1. Experimental Results. With respect to the field experiment conducted on two similar buildings in Jinxing Village, Hanzhong City, this section exhibits the temperature of the roof tiles, the air temperature in the attic space, the temperature of the attic floor, the ceiling temperature, and the temperature of the second-floor bedroom in the test residences. Figures 9 and 10 show the outdoor conditions during the field test period (from July 27, 2019, to July 28, 2019). During the test period, the peak total radiation intensity was $974 \mathrm{~W} / \mathrm{m}^{2}$, and the average radiation intensity was $676 \mathrm{~W} / \mathrm{m}^{2}$, while the direct solar radiation intensity accounted for $76 \%$ of the total radiation intensity. Based on the experimental results, the solar radiation intensity was higher during summer. The average outdoor air temperature was $29.5 \%$, while the daily temperature varied by $5^{\circ} \mathrm{C}$.

Figure 11 shows the temperature of the roof, attic floor, and ceiling of both residences. It can be seen from this figure that there was not much difference in the bottom surface temperature of the roof tiles in both buildings; however, with the use of radiant barriers, there was a significant difference in the inner surface temperature of the roof. The maximum bottom surface temperature of the radiant barriers in Residence 2 was approximately $15.1^{\circ} \mathrm{C}$ lower than that in Residence 1. This goes to show that the thermal insulation effect of the radiant barriers was significant. At the same time, it can also be seen that, in 
TABLE 3: Outdoor sol-air temperatures on the winter solstice.

\begin{tabular}{lcccccc}
\hline \multicolumn{7}{c}{ Temperature on the winter solstice $\left({ }^{\circ} \mathrm{C}\right)$} \\
Time & Level & South & East & Western & North & Outdoor air \\
\hline $1: 00$ & -4.3 & -2.25 & -2.25 & -2.25 & -2.25 & -0.2 \\
$2: 00$ & -4.68 & -2.64 & -2.64 & -2.64 & -2.64 & -0.6 \\
$3: 00$ & -4.88 & -2.84 & -2.84 & -2.84 & -2.84 & -0.8 \\
$4: 00$ & -4.86 & -2.83 & -2.83 & -2.83 & -2.83 & -0.8 \\
$5: 00$ & -4.65 & -2.62 & -2.62 & -2.62 & -2.62 & -0.6 \\
$6: 00$ & -4.53 & -2.52 & -2.52 & -2.52 & -2.52 & -0.5 \\
$7: 00$ & -4.54 & -2.52 & -2.52 & -2.52 & -2.52 & -0.5 \\
$8: 00$ & -4.65 & -2.62 & -2.62 & -2.62 & -2.62 & -0.6 \\
$9: 00$ & -2.98 & -1.3 & -1.23 & -1.73 & -1.73 & -0.7 \\
$10: 00$ & -0.8 & 0.21 & 0.04 & -0.58 & -0.58 & -0.8 \\
$11: 00$ & 1.2 & 1.56 & 1.06 & 0.62 & 0.62 & -0.6 \\
$12: 00$ & 2.21 & 2.12 & 1.56 & 1.43 & 1.43 & -0.2 \\
$13: 00$ & 0.56 & 0.96 & 0.88 & 0.89 & 0.88 & 0.4 \\
$14: 00$ & -0.42 & 0.61 & 0.59 & 0.6 & 0.59 & 1.1 \\
$15: 00$ & 0.01 & 1.15 & 1.12 & 1.14 & 1.12 & 1.8 \\
$16: 00$ & -0.37 & 1.18 & 1.14 & 1.18 & 1.14 & 2.4 \\
$17: 00$ & -1.27 & 0.76 & 0.76 & 0.76 & 0.76 & 2.8 \\
$18: 00$ & -1.18 & 0.86 & 0.86 & 0.86 & 0.86 & 2.9 \\
$19: 00$ & -1.19 & 0.86 & 0.86 & 0.86 & 0.86 & 2.9 \\
$20: 00$ & -1.28 & 0.76 & 0.76 & 0.76 & 0.76 & 2.8 \\
$21: 00$ & -1.44 & 0.58 & 0.58 & 0.58 & 0.58 & 2.6 \\
$22: 00$ & -1.92 & 0.09 & 0.09 & 0.09 & 0.09 & 2.1 \\
$23: 00$ & -2.31 & -0.3 & -0.3 & -0.3 & -0.3 & 1.7 \\
$0: 00$ & -2.21 & -0.2 & -0.2 & -0.2 & -0.2 & 1.8 \\
Average & -2.1 & -0.46 & -0.51 & -0.58 & -0.58 & 0.77 \\
\hline & & & & & &
\end{tabular}

Residence 1, where radiant barriers were installed, the maximum bottom surface temperature of the radiant barriers was approximately $17.2^{\circ} \mathrm{C}$ lower than the bottom surface temperature of the roof tiles. There are two reasons to explain the large temperature differences. One of the main reasons is that as aluminum foil bubble composites are adhered to the rafters, small air cavities remain between the aluminum foil and the clay tiles. The presence of air cavities enables both sides of the aluminum foil to be fully utilized, thereby effectively reducing radiant heat transfer from the roof tiles to the attic floor. On the other hand, since the radiant barriers block heat transfer to the attic floor, the heat trapped in the attic space will heat up the inner surface of the roof tiles, thus leading to an increase in the temperature of the bottom of the clay tiles. The bottom surface temperature of the attic floor was always higher than the temperature of the floor without radiant barriers. Table 4 summarizes the characteristics of the inner surface temperature of the roof and bottom surface temperature of the floor (ceiling).

Table 5 shows the maximum, minimum, and average temperatures of the attic space and bedroom. Figure 12 displays the temperature variation in the attic space and bedroom. Based on Figure 12, the use of radiant barriers significantly improved the thermal stability of the attic space, resulting in a $7^{\circ} \mathrm{C}$ drop in the peak temperature of the attic space during daytime, a $2.1^{\circ} \mathrm{C}$ decrease in the average temperature of the attic space, and a slight increase in the temperature of the attic space during nighttime. The bedroom temperature in Residence 1 was always lower than the

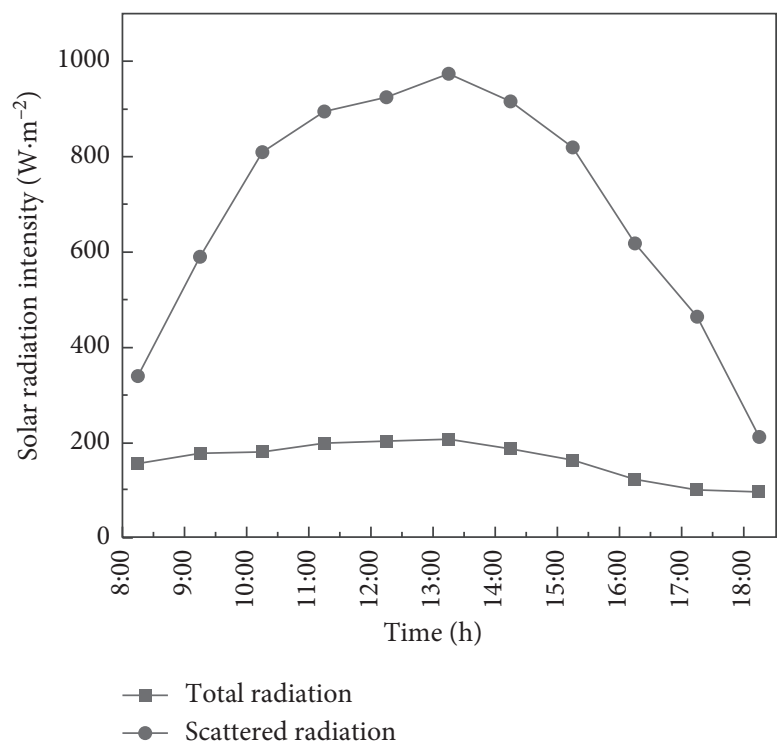

FIgURE 9: Solar radiation intensity.

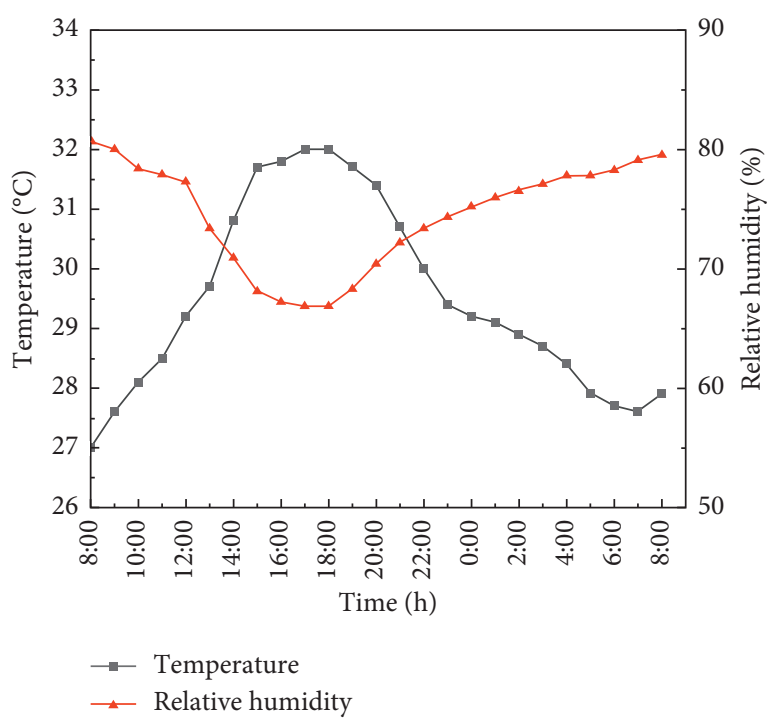

FIgURE 10: Outdoor air temperature and humidity.

bedroom temperature in Residence 2, while the average bedroom temperature dropped by $1.1^{\circ} \mathrm{C}$.

3.2. Validation of the CFX Model with Measured Data. This section compares the estimations made using the CFX model and the experimental data recorded in both test residences. This study constructed two numerical models using the parameters in Tables 1 and 2 and performed numerical simulations, in which all temperatures in the CFX simulation were highly consistent with the experimental data. To illustrate the CFX simulation results, Figure 13 compares the air temperatures in the attic space of Residence 1 and Residence 2 obtained from the simulation and the experiment. Table 6 shows the average difference between the simulation results and the experiment results. According to this table, the largest average temperature difference was $0.3^{\circ} \mathrm{C}$. 


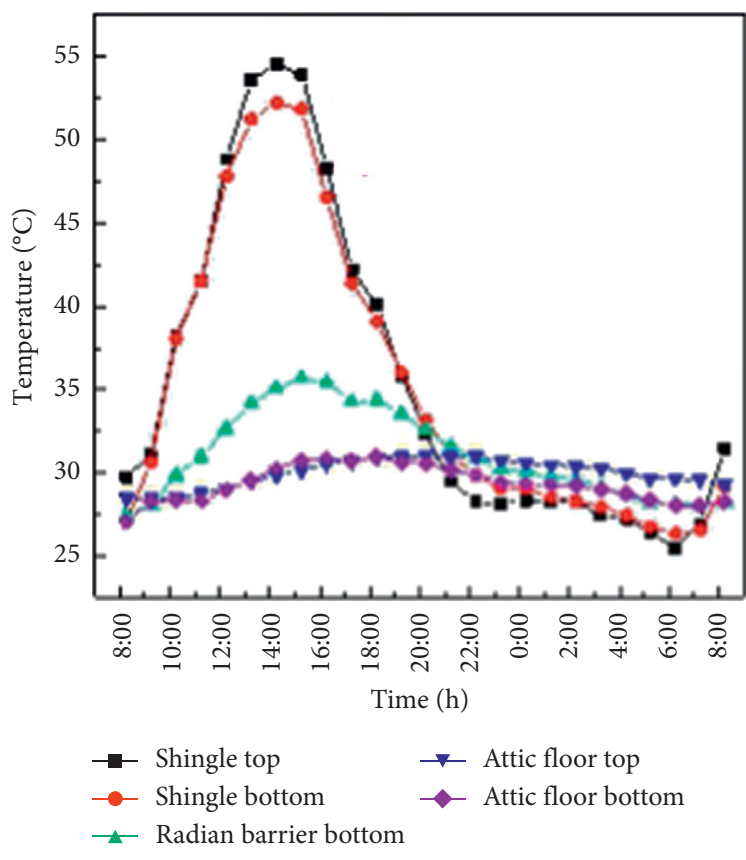

(a)

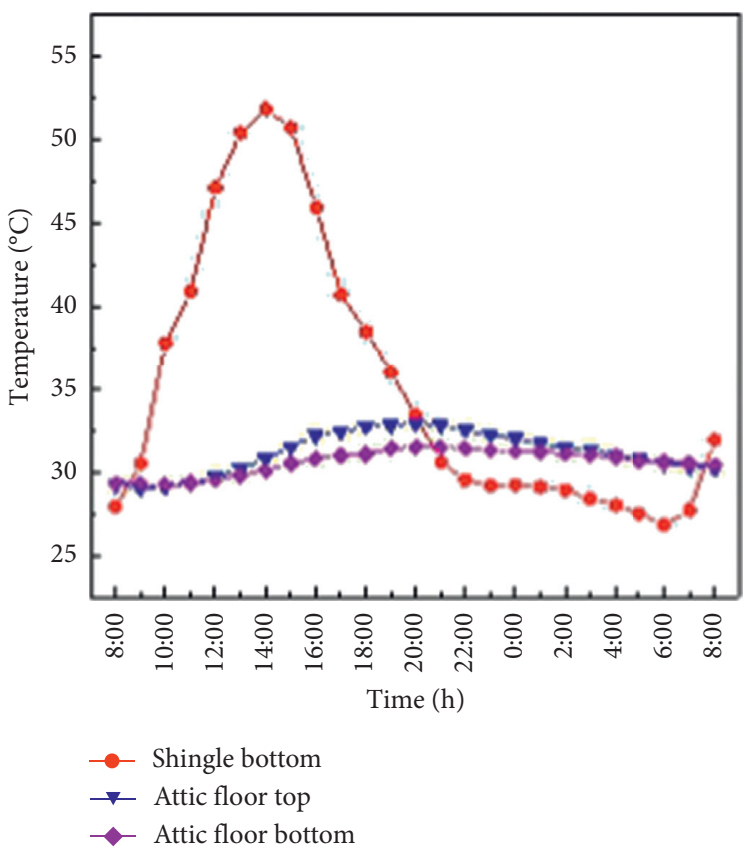

(b)

FIGURE 11: Variation of surface temperature in Residence 1 (a) and Residence 2 (b).

TABLE 4: Surface temperature with and without radiant barriers.

\begin{tabular}{lcccc}
\hline & \multicolumn{2}{c}{ Inner surface of roof } & \multicolumn{2}{c}{ Bottom surface of floor } \\
& With radiant barriers & Without radiant barriers & With radiant barriers & Without radiant barriers \\
\hline Maximum temperature $\left({ }^{\circ} \mathrm{C}\right)$ & 35.6 & 50.7 & 31.0 & 31.5 \\
Minimum temperature $\left({ }^{\circ} \mathrm{C}\right)$ & 28.0 & 26.8 & 28.0 & 29.3 \\
Average temperature $\left({ }^{\circ} \mathrm{C}\right)$ & 31.0 & 35.0 & 29.3 & 30.6 \\
\hline
\end{tabular}

TABLE 5: Air temperature with and without radiant barriers.

\begin{tabular}{|c|c|c|c|c|}
\hline & \multicolumn{2}{|c|}{ Residence 1 with radiant barriers } & \multicolumn{2}{|c|}{ Residence 2 without radiant barriers } \\
\hline & Attic space & Bedroom & Attic space & Bedroom \\
\hline Maximum temperature $\left({ }^{\circ} \mathrm{C}\right)$ & 33.8 & 31 & 40.5 & 31.6 \\
\hline Minimum temperature $\left({ }^{\circ} \mathrm{C}\right)$ & 29.1 & 27.4 & 28.4 & 29.4 \\
\hline Average temperature $\left({ }^{\circ} \mathrm{C}\right)$ & 31.8 & 29.4 & 33.9 & 30.5 \\
\hline
\end{tabular}

\subsection{Contribution of Radiant Heat Transfer and Heat Con-} duction to Thermal Insulation Performance. With respect to the tested radiant barrier roofs, aluminum foil bubble composites reduced the temperature of the attic floor in two ways: (1) radiant heat transfer, in which the surface emissivity of the radiant barriers decreased, and (2) heat conduction, in which the thermal resistance of the insulating materials between the layers of the radiant barriers decreased. The measured results exhibited the combined effect of both radiant heat transfer and heat conduction.

To understand the specific contribution of each heat transfer mode, this study simulated the variation of peak temperature of the second-floor ceiling under three operating conditions (Table 7). Operating Conditions A, B, and C represented the conditions that aluminum foil bubble composites were applied, that there was no thermal resistance in aluminum foil bubble composites, and that aluminum foil bubble composites were not applied, respectively. By comparing both Operating Conditions $\mathrm{A}$ and $\mathrm{C}$, it can be found that aluminum foil bubble composites can effectively reduce the peak temperature of the indoor ceiling, which decreased by $1.7^{\circ} \mathrm{C}$. This is the result of the combined effect of both radiant heat transfer and heat conduction. According to the comparison between Operating Conditions B and C, aluminum foil bubble composite, with thermal resistance remaining constant, not only changed the emissivity of the ceiling but also reduced the peak ceiling temperature by $1.1^{\circ} \mathrm{C}$. This is the result of radiant heat transfer. Based on these results, it can be concluded that radiant heat transfer and heat conduction account for $65 \%$ and $35 \%$, respectively, in the thermal insulation effect of aluminum foil 


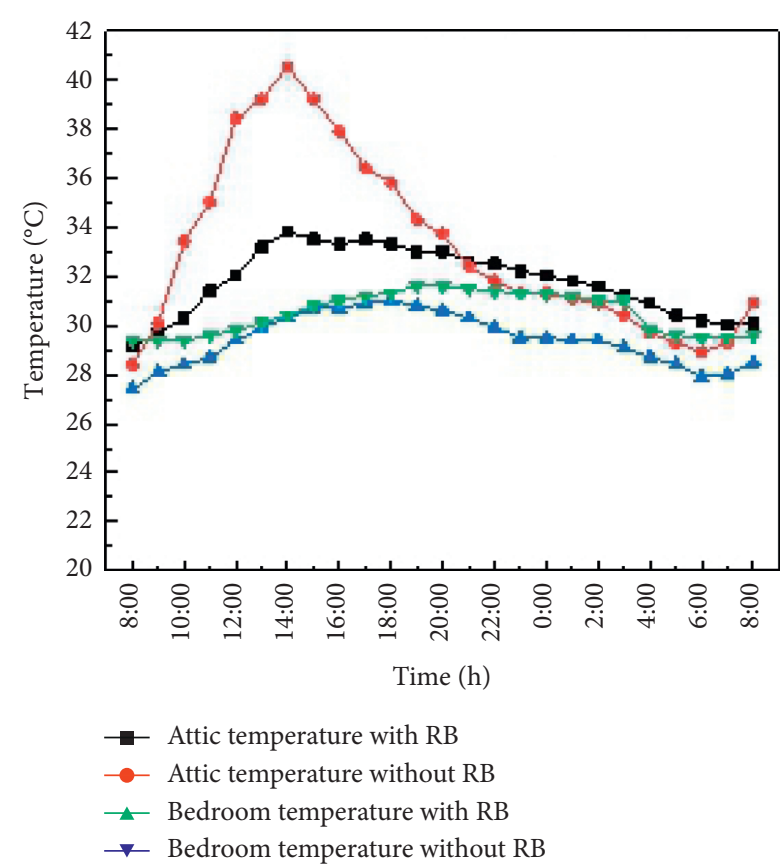

FIGURE 12: Variation of temperature in the attic space and bedroom with and without radiant barriers.

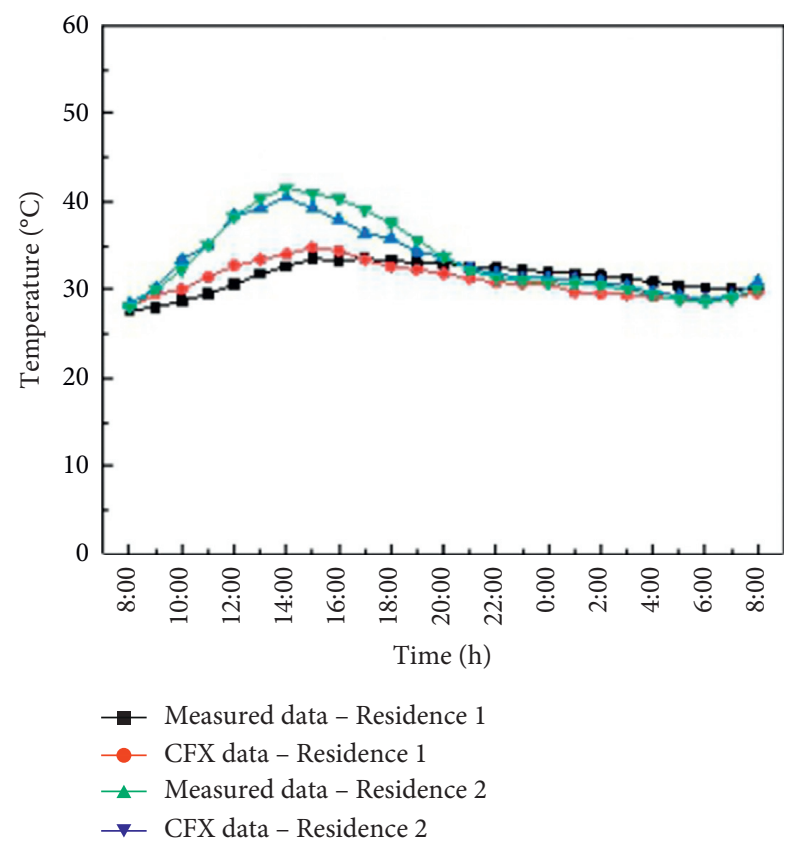

FIGURE 13: Comparison between estimated and measured values.

bubble composites. Therefore, the low emissivity of aluminum foil bubble composite has a greater impact on its thermal insulation performance.

3.4. Effect of Emissivity and Thermal Resistance on Ceiling Temperature. In this model, the initial thermal resistance of
TABLE 6: Air temperature in the attic space from the simulation and the experiment.

\begin{tabular}{lccc}
\hline & \multicolumn{3}{c}{ Attic air temperature $\left({ }^{\circ} \mathrm{C}\right)$} \\
& Measured avg. & Modeled avg. & Absolute difference \\
\hline Residence 1 & 31.4 & 31.1 & 0.3 \\
Residence 2 & 33.2 & 33.4 & 0.2 \\
\hline
\end{tabular}

aluminum foil bubble composites used was $0.075 \mathrm{~m}^{2} \mathrm{~K} / \mathrm{W}$, and the emissivity values of aluminum foil bubble composites used were $0.1,0.3,0.5,0.7$, and 0.9 . Figure 14 shows the variation of the maximum temperature of the secondfloor bedroom ceiling with emissivity. As expected, emissivity has a greater effect on ceiling temperature. An emissivity of less than 0.3 can effectively reduce peak ceiling temperature, which also demonstrates the advantage of applying low-emissivity materials to the inner surface of the roof.

The initial emissivity of aluminum foil bubble composites used was 0.25 , while the thermal resistance values of aluminum foil bubble composites used were $R=0.5,2,3.5$, and 5. Figure 15 exhibits the effect of thermal resistance of the radiant barriers on peak ceiling temperature. Based on this figure, it can be observed that as thermal resistance increases, the inner surface temperature of the roof decreases significantly. When thermal resistance continues to increase from $2 \mathrm{~m}^{2} \mathrm{~K} / \mathrm{W}$, the temperature of the indoor ceiling decreases slowly. Therefore, it is not necessary to have high thermal resistance. When thermal resistance is less than $2 \mathrm{~m}^{2} \mathrm{~K} / \mathrm{W}$, thermal resistance has a greater effect on peak temperature. Based on the analysis of thermal performance and cost, low thermal resistance results in better performance than high thermal resistance. Hence, it is recommended to use radiant barrier materials with an emissivity of less than 0.3 and a thermal resistance of no more than $2 \mathrm{~m}^{2} \mathrm{~K} / \mathrm{W}$.

3.5. Thermal Insulation Performance of Radiant Barrier Roof during Winter. Heat entering indoors through the roof has to be reduced during summer. However, a roof requires more heat to enter indoors during winter. Therefore, the use of radiant barriers is beneficial to heat proofing during summer but is unfavorable to heating during winter. Hence, this study investigated the thermal insulation performance of radiant barrier roofs during winter.

Table 8shows the simulated air temperature in the attic space during winter. As thermal resistance is present in aluminum foil bubble composites, air temperature in the attic space where aluminum foil bubble composites were used was always higher than that in the attic space without radiant barriers. The maximum and minimum air temperatures in the attic space rose by $3.3^{\circ} \mathrm{C}$ and $5.4^{\circ} \mathrm{C}$, respectively. The use of aluminum foil bubble composites enhanced the stability of air temperature in the attic space. Hence, aluminum foil bubble composites are favorable to roof insulation during winter. 
TABLE 7: Simulation results under three operating conditions.

\begin{tabular}{lccr}
\hline Operating condition & $R$-value $\left(\mathrm{m}^{2} \mathrm{~K} / \mathrm{W}\right)$ & $\mathcal{1}$ & Maximum ceiling temperature $\left({ }^{\circ} \mathrm{C}\right)$ \\
\hline A & 0.075 & 0.25 & 29.9 \\
B & 0 & 0.25 & 30.5 \\
C & 0 & 0.95 & 31.6 \\
\hline
\end{tabular}

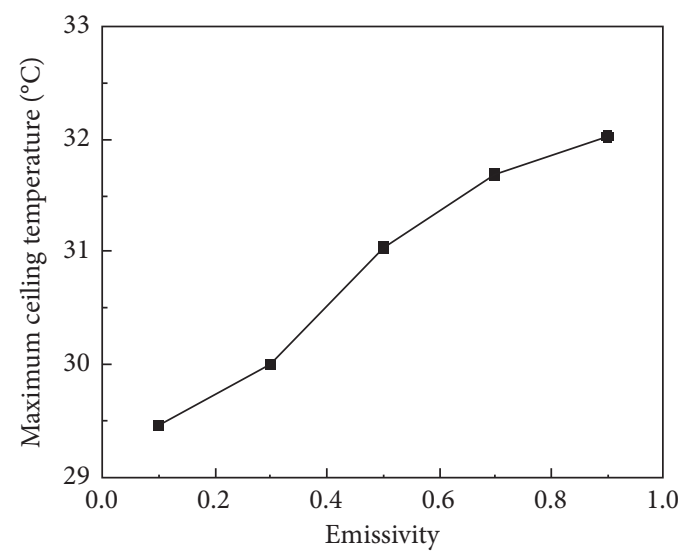

FIGURE 14: Maximum ceiling temperature at different values of emissivity.

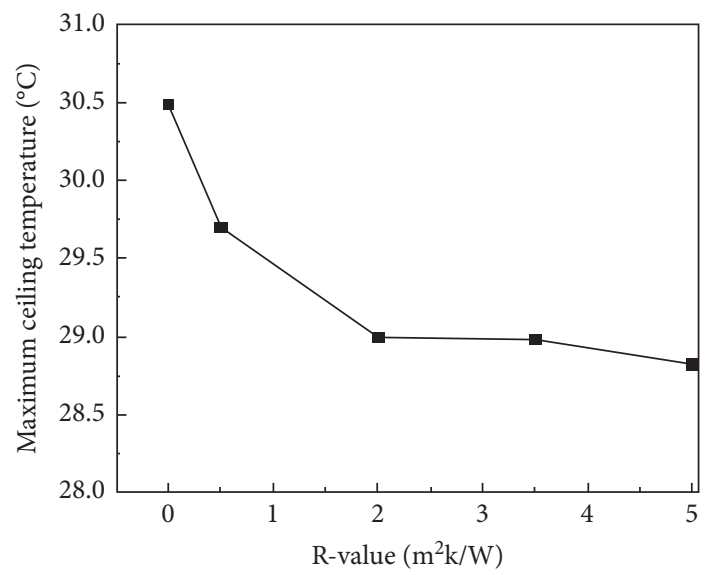

FIgURE 15: Maximum ceiling temperature at different values of thermal resistance.

TABle 8: Air temperature in the attic space with and without radiant barriers.

\begin{tabular}{lcc}
\hline & & Attic space \\
& With radiant barriers & Without radiant barriers \\
\hline Maximum temperature $\left({ }^{\circ} \mathrm{C}\right)$ & 9.6 & 6.3 \\
Minimum temperature $\left({ }^{\circ} \mathrm{C}\right)$ & 8.2 & 2.8 \\
Average temperature $\left({ }^{\circ} \mathrm{C}\right)$ & 9.1 & 4.9 \\
\hline
\end{tabular}

\section{Conclusion}

This study investigated the thermal insulation performance of radiant barrier roofs. The following conclusions were drawn:

(1) The results proved the superiority of the thermal insulation performance of radiant barrier roofs. The average bedroom temperature in the residence to which aluminum foil bubble composites were applied dropped by $1.1^{\circ} \mathrm{C}$ compared to the traditionally constructed residence.

(2) In aluminum foil bubble composites, radiant heat transfer contributed $65 \%$ to the thermal insulation effect of radiant barriers. It also explained the 
advantage of applying low-emissivity materials to the inner surface of the roof. Based on the analysis of thermal performance and cost, low thermal resistance resulted in better performance than high thermal resistance. It is recommended to use radiant barrier materials with an emissivity of less than 0.3 and a thermal resistance of no more than $2 \mathrm{~m}^{2} \mathrm{~K} / \mathrm{W}$.

(3) Aluminum foil bubble composites have a positive insulating effect during winter due to the presence of thermal resistance, thereby facilitating the widespread use of radiant barrier roofs in buildings located in hot-summer/cold-winter zones.

\section{Data Availability}

The data used to support the findings of this study are included within the supplementary information file.

\section{Conflicts of Interest}

The authors declare that there are no conflicts of interest regarding the publication of this paper.

\section{Acknowledgments}

This research was supported by the National Natural Science Foundation of China under the project titled "Thermal Environment Creation and Low-Consumption Building Mode for Buildings in the Qinba Mountains" (51678483).

\section{Supplementary Materials}

Excels a-d: experimental data. Excels e-g: simulated data. Excel h: outdoor sol-air temperatures calculation. (Supplementary Materials)

\section{References}

[1] T. Huo, H. Ren, X. Zhang et al., "China's energy consumption in the building sector: a statistical yearbook-energy balance sheet based splitting method," Journal of Cleaner Production, vol. 185, pp. 665-679, 2018.

[2] Y. Zhang, C.-Q. He, B.-J. Tang, and Y.-M. Wei, "China's energy consumption in the building sector: a life cycle approach," Energy and Buildings, vol. 94, pp. 240-251, 2015.

[3] K. C. K. Vijaykumar, P. S. S. Srinivasan, and S. Dhandapani, "A performance of hollow clay tile (HCT) laid reinforced cement concrete (RCC) roof for tropical summer climates," Energy and Buildings, vol. 39, no. 8, pp. 886-892, 2007.

[4] A. L. S. Chan and T. T. Chow, "Evaluation of Overall Thermal Transfer Value (OTTV) for commercial buildings constructed with green roof," Applied Energy, vol. 107, pp. 10-24, 2013.

[5] K. M. Al-Obaidi, M. Ismail, and A. M. Abdul Rahman, "Design and performance of a novel innovative roofing system for tropical landed houses," Energy Conversion and Management, vol. 85, no. 9, pp. 488-504, 2014.

[6] F. Isaia, S. Fantucci, A. Capozzoli, and M. Perino, "Thermal bridges in vacuum insulation panels at building scale," Proceedings of the Institution of Civil Engineers - Engineering Sustainability, vol. 170, pp. 47-60, 2016.

[7] M. Alam, H. Singh, S. Suresh, and D. A. G. Redpath, "Energy and economic analysis of Vacuum Insulation Panels (VIPs) used in non-domestic buildings," Applied Energy, vol. 188, pp. 1-8, 2017.

[8] M. Musy, L. Malys, and C. Inard, "Assessment of direct and indirect impacts of vegetation on building comfort: a comparative study of lawns, green walls and green roofs," Procedia Environmental Sciences, vol. 38, pp. 603-610, 2017.

[9] L. Malys, M. Musy, and C. Inard, "Direct and indirect impacts of vegetation on building comfort: a comparative study of lawns, green walls and green roofs," Energies, vol. 9, no. 1, p. 32, 2016.

[10] A. L. Pisello, V. L. Castaldo, G. Pignatta, F. Cotana, and M. Santamouris, "Experimental in-lab and in-field analysis of waterproof membranes for cool roof application and urban heat island mitigation," Energy and Buildings, vol. 114, pp. 180-190, 2016.

[11] S. Wang and Z. Shen, "Energies, vol. 5, pages 3218-3232: impacts of ventilation ratio and vent balance on cooling load and air flow of naturally ventilated attics," Energies, vol. 5, no. 12, pp. 1069-1077, 2012.

[12] M. Santamouris, "Cooling the cities-a review of reflective and green roof mitigation technologies to fight heat island and improve comfort in urban environments," Solar Energy, vol. 103, pp. 682-703, 2014.

[13] H. Akbari and S. Konopacki, "Calculating energy-saving potentials of heat-island reduction strategies," Energy Policy, vol. 33, no. 6, pp. 721-756, 2005.

[14] A. Scherba, D. J. Sailor, T. N. Rosenstiel, and C. C. Wamser, "Modeling impacts of roof reflectivity, integrated photovoltaic panels and green roof systems on sensible heat flux into the urban environment," Building and Environment, vol. 46, no. 12, pp. 2542-2551, 2011.

[15] A. Spanaki, T. Tsoutsos, and D. Kolokotsa, "On the selection and design of the proper roof pond variant for passive cooling purposes," Renewable and Sustainable Energy Reviews, vol. 15, no. 8, pp. 3523-3533, 2011.

[16] A. Tokuç, T. Başaran, and S. C. Yesügey, “An experimental and numerical investigation on the use of phase change materials in building elements: the case of a flat roof in Istanbul," Energy and Buildings, vol. 102, no. 43, pp. 91-104, 2015.

[17] X. Chen, L. Wang, Z. Liu, Y. Qin, and T. Bao, "Lowering emissivity of concrete roof tile's underside cuts down heat entry to the building," Advances in Materials Science and Engineering, vol. 2019, Article ID 5438321, 8 pages, 2019.

[18] Y. Qin, Y. He, B. Wu, S. Ma, and X. Zhang, "Regulating top albedo and bottom emissivity of concrete roof tiles for reducing building heat gains," Energy and Buildings, vol. 156, pp. 218-224, 2017.

[19] M. Kolokotroni, B. L. Gowreesunker, and R. Giridharan, "Cool roof technology in London: an experimental and modelling study," Energy and Buildings, vol. 67, pp. 658-667, 2013.

[20] S. Boixo, M. Diaz-Vicente, A. Colmenar, and M. A. Castro, "Potential energy savings from cool roofs in Spain and Andalusia," Energy, vol. 38, no. 1, pp. 425-438, 2012.

[21] K. Saafi and N. Daouas, "A life-cycle cost analysis for an optimum combination of cool coating and thermal insulation of residential building roofs in Tunisia," Energy, vol. 152, pp. 925-938, 2018.

[22] M. A. Medina, "Effects of shingle absorptivity, radiant barrier emissivity, attic ventilation flowrate, and roof slope on the performance of radiant barriers," International Journal of Energy Research, vol. 24, no. 8, pp. 665-678, 2000.

[23] M. A. Medina, "On the performance of radiant barriers in combination with different attic insulation levels," Energy and Buildings, vol. 33, no. 1, pp. 31-40, 2000. 
[24] J. W. Rish and J. A. Roux, "Heat transfer analysis of fiberglass insulations with and without foil radiant barriers," Journal of Thermophysics Heat Transfer, vol. 1, no. 1, pp. 43-49, 2015.

[25] P. Fairey and M. Swami, "Attic radiant barrier systems: a sensitivity analysis of performance parameters," International Journal of Energy Research, vol. 16, no. 1, pp. 1-12, 2010.

[26] F. Miranville, H. Boyer, P. Lauret, and F. Lucas, "A combined approach for determining the thermal performance of radiant barriers under field conditions," Solar Energy, vol. 82, no. 5, pp. 399-410, 2008.

[27] M. Ferreira and H. Corvacho, "The effect of the use of radiant barriers in building roofs on summer comfort conditions - a case study," Energy and Buildings, vol. 176, pp. 163-178, 2018.

[28] M. A. Medina, "Effects of shingle absorptivity, radiant barrier emissivity, attic ventilation flowrate, and roof slope on the performance of radiant barriers," International Journal of Energy Research, vol. 24, no. 8, pp. 665-678, 2015.

[29] J. Kosny, A. D. Fontanini, N. Shukla et al., "Thermal performance analysis of residential attics containing high performance aerogel-based radiant barriers," Energy and Buildings, vol. 158, pp. 1036-1048, 2018.

[30] D. Li, Y. Zheng, C. Liu, H. Qi, and X. Liu, "Numerical analysis on thermal performance of naturally ventilated roofs with different influencing parameters," Sustainable Cities and Society, vol. 22, pp. 86-93, 2016.

[31] J. Deblois, M. Bilec, and L. Schaefer, "Simulating home cooling load reductions for a novel opaque roof solar chimney configuration," Applied Energy, vol. 112, no. 4, pp. 142-151, 2013.

[32] S. Tong and L. Hua, "An efficient model development and experimental study for the heat transfer in naturally ventilated inclined roofs," Building Environment, vol. 81, pp. 296-308, 2014.

[33] J. H. Q. Zhang, Chinese Typical Meteorological Database for Buildings, China Machine Press, Beijing, China, 2004.

[34] Z. Q. Yan Qisen, Thermal Process of Building, China Buliding Industry Press, Beijing, China, 1986. 